\title{
REPENSANDO AS RELAÇÕES URBANO-RURAIS NO ENSINO ESCOLAR: um diálogo entre professores
}

\author{
RETHINKING URBAN-RURAL RELATIONS IN SCHOOL EDUCATION: a dialogue among teachers
}

\author{
REPENSAR LAS RELACIONES URBANO-RURALES EN LA EDUCACIÓN ESCOLAR: un dialogo entre profesores
}

\section{RESUMO}

Este artigo considera as possibilidades de pesquisas geográficas sobre as relações urbano-rurais e seus desdobramentos no ensino de Geografia nas escolas. Diversas disciplinas têm discutido as características formais dos espaços rurais (várias delas baseadas na visão dicotômica das relações urbano-rurais), bem como os conceitos adequados para estudar sua reconfiguração. Pode-se argumentar que uma importante influência da urbanidade contemporânea pode agora ser encontrada nas áreas rurais. Assim, sugerimos a noção de "urbanidades no rural", consideradas como manifestações de espaços híbridos, nos quais o urbano e o rural se entrecruzam e interagem em muitas formas de combinações. Essa abordagem pode representar alternativas analíticas - e atenuar as limitações de algumas perspectivas. A partir desse debate, o artigo visa construir um diálogo entre professores de Geografia acerca das relações urbano-rurais, apresentando contribuições das noções expostas (e seus desdobramentos) para o ensino de Geografia e, em específico, de Geografia Rural - partindo da perspectiva de um espaço integrado e multidimensional.

Palavras-chave: Ensino de Geografia. Relações cidade-campo. Relações urbano-rurais. Urbanidades no rural. Geografia Rural.

\section{ABSTRACT}

This article considers the geographical research on urban-rural relations and its possibilities in the teaching of Geography in schools. Several disciplines have discussed the formal characteristics of rural spaces (several based on the dichotomous view of urban-rural relations), as well as the appropriate concepts for studying their reconfiguration. It can be argued that an important influence of contemporary urbanity can now be found in rural areas. Thus, we suggest the idea of "urbanities on rural areas", considered as manifestations of hybrid spaces, in which the urban and rural intertwine and interact in all manners of combinations. This approach can present other analytical alternatives - and mitigate the limitations of some perspectives. Based on this debate, the article aims to build a dialogue between geography teachers about urban-rural relations, presenting contributions from the exposed notions (and their consequences) for the teaching of geography and, specifically, of Rural Geography - starting from a perspective of an integrated and multidimensional space.

Keywords: Geography teaching. City-countryside relations. Urban-rural relations. Urbanities on rural areas. Rural Geography.

\section{RESUMEN}

Este artículo considera las posibilidades de la investigación geográfica sobre las relaciones urbano-rurales y sus consecuencias en la enseñanza de la Geografía en las escuelas. Varias disciplinas han discutido las características formales de los espacios rurales (muchas basadas en la visión dicotómica de las relaciones urbano-rurales), así como los conceptos adecuados para estudiar su reconfiguración. Se puede argumentar que ahora se puede encontrar una influencia importante de la urbanidad contemporánea en las áreas rurales. Así, sugerimos la noción de "urbanidades en lo rural", consideradas como manifestaciones

\author{
João Rua ${ }^{a}$ \\ Joana Cruz de Simoni ${ }^{b}$ \\ a Pontifícia Universidade Católica do Rio de \\ Janeiro (PUC-Rio)
}

DOI: $10.12957 /$ geouerj.2020.55729

Correpondência: joaorua@uol.com.br

Recebido em: 20 set. 2020

Revisado em: 30 out 2020

Aceito em: 30 out. 2020 
de espacios híbridos, en los que lo urbano y lo rural se entrelazan e interactúan en todas las formas de combinaciones. Este enfoque puede representar otras alternativas analíticas y mitigar las limitaciones de algunas perspectivas. A partir de este debate, el artículo tiene como objetivo construir un diálogo entre profesores de geografía sobre las relaciones urbano-rurales, presentando aportes de las nociones expuestas (y sus consecuencias) para la enseñanza de la Geografía y, en concreto, de la Geografía Rural - partiendo de una perspectiva de un espacio integrado y multidimensional.

Keywords: Enseñanza de la geografía. Relaciones ciudad-campo. Relaciones urbano-rurales. Urbanidades en lo rural. Geografía Rural

\section{INTRODUÇÃO}

Assiste-se, hoje em dia, a uma espécie de "restauração conservadora" da sociedade brasileira que se explicita, dentre outras manifestações, na educação - que ora é perseguida, ora é relegada a segundo plano. Nesse contexto, não se pode aceitar nem a excessiva valorização do papel iluminista da escola e nem o da reprodução pura e simples das relações de poder. A escola é um dos locais onde se manifestam as contradições da sociedade, mas é, ao mesmo tempo, um local privilegiado para o questionamento dessa lógica e da busca da construção de um cidadão novo (crítico, capaz de atuar na transformação da sociedade).

Nesse ponto, é necessário remeter-se à importância da atuação dos professores (atuando como transformadores da sociedade) para se perceber que, dentro do quadro geral de precarização do trabalho, é cada vez mais difícil a ação destes (e, em específico, dos professores de Geografia) como elementos de modificação social através da dessa ciência na escola.

Educar é conscientizar e, assim, a educação é um ato essencialmente político. Portanto ninguém educa ninguém sem uma proposta política. Isto não significa tentar reduzir tudo ao político, como se o político (ou o econômico, ou o cultural), isoladamente, explicasse tudo. Significa não ignorar os prolongamentos políticos do ato pedagógico. Conscientizar, no caso da maioria dos alunos, que é composta de não trabalhadores, é despertar a consciência, tarefa desenvolvida pelo professor. Mas, também aqui, deve-se relativizar esta prática. O trabalho de "conscientizar" (na escola) deve ser entendido como ajudar a desenvolver a logicidade, a criticidade e a criatividade, através de atividades e da relação entre conteúdo e a vida cotidiana do aluno, bem como com os problemas que enfrenta.

Acreditamos que o professor tem uma contribuição específica na transformação estrutural da sociedade. Tal contribuição se consubstanciou na instrumentalização (ferramentas de caráter geográfico, histórico, matemático) que o professor seja capaz de colocar nas mãos dos alunos em permanente exercício de produção conjunta do conhecimento. Isso vai depender da forma como eles percebam os vínculos entre sua prática e a prática social global. Assim, é necessário que o professor se veja como intelectual transformador e para isso é preciso que tenha motivação política para fazer um trabalho subversivo (no sentido de renovador, crítico, criativo, autônomo) e, assim, possa contribuir para a mudança da 
sociedade - parafraseando Milton Nascimento, é preciso ir aonde o aluno está, participar mais da sua vida e valorizar mais suas experiências. Sua prática docente também exige um constante reinventar-se, uma vez que o espaço global está sempre em transformação.

Este processo de construção do conhecimento significa que os professores da educação básica devem participar (como vêm fazendo) das novas concepções da Geografia, disciplina que, ao nosso ver, se torna cada vez mais fundamental para o cidadão de hoje que vive num meio complexo de elementos inter-relacionados. Fazer com que o aluno descubra as relações entre os homens e os lugares; fazê-lo familiarizar-se com problemas que não cessam de manifestar-se numa dinâmica que se enriquece dia-a-dia, incentivá-lo a perceber que as relações sociedade-natureza dependem das relações sociedade-sociedade; permitir-lhe avaliar criticamente o espaço em que vive e convive, integrando-se ao seu meio, são funções da Geografia em qualquer nível de ensino. Tal integração abrangerá várias escalas, desde a sala de aula até o mundo, passando pela compreensão de uma visão mais integral do aluno, parte constituinte e construtor desse complexo social - o espaço construído.

Essas afirmações vão ao encontro dos apontamentos de geógrafos e geógrafas como, por exemplo, Doreen Massey que, no momento em que a Inglaterra atravessava sérios problemas de desenvolvimento regional desigual, ressaltou a relevância da Geografia para a intervenção em políticas públicas, para a política em si mesma e para o estudo das relações sociedade-natureza (MASSEY, 2001, p. 25). Mais recentemente, o jornal The Guardian, também inglês, propõe que uma nova estrela científica estaria nascendo - a Geografia - percebida como um campo de conhecimento extremamente útil, com forte reconhecimento social (THE GUARDIAN, 2015).

Nesse sentido, coloca-se um importante papel a ser desempenhado pelo geógrafo e pelo professor de Geografia. São muitas as entradas possíveis para que esse papel seja desempenhado - fato é que não podemos esquivar-nos dele. Se iniciamos este trabalho apontando um contexto de crise, devemos apontar que o momento que atravessamos (a pandemia de Covid-19) acentua essa crise. Por outro lado, coloca a ciência geográfica - e sua relevância - mais uma vez na agenda. Como superar tal crise sem pensar outras geografias - outras formas de nos relacionar e produzir o espaço? Defendemos, aqui, o caráter do espaço-totalidade ${ }^{1}$, em constante movimento e transformação, cada vez mais integrado. A disseminação do vírus expõe, de forma violenta, esse caráter.

Isto ocorre, dentre tantos motivos, pela explicitação de um espaço que não é dicotômico, não é parcelar e não é unidimensional. Não podemos encarar a citada crise se não o compreendermos como integrado (ora, ao mesmo tempo em que atitudes isoladas não são de fato efetivas para controlar a disseminação do vírus, também estas podem ter efeitos no espaço total), fluido (onde circulam materialidades e imaterialidades) e multidimensional (onde se desenvolvem relações econômicas, mas também bióticas, culturais, ambientais, sociais, técnicas, subjetivas...).

\footnotetext{
${ }^{1}$ Por totalidade compreende-se que a análise da realidade não se dá a partir da soma das partes, e deve-se encará-la em relação a outras totalidades, igualmente abertas e em permanente desdobramento na análise efetuada, portanto todos objetos, ações, sujeitos, processos são vinculados entre si, se determinam e se inter-relacionam.
} 
Seguindo ainda no exemplo da relação do espaço com a pandemia (e da perspectiva a partir da qual o encaramos), podemos nos encaminhar para o tema específico sobre o qual nos debruçaremos. Rural e urbano, ainda que diferentes e desiguais, não constituem fragmentos isolados do espaço, nem podem ser encarados de maneira dicotômica. Os efeitos da pandemia não reconhecem os limites administrativos e, de maneiras diversas, abarca o espaço como um todo. Como postula Cavalcanti (2020), a crise que atravessamos oferece oportunidades (econômicas) para alguns, e riscos e ampliação de vulnerabilidades, para outros - e esta reflexão vale para a totalidade do espaço.

Nesse sentido, se o (pretenso) menor grau de aglomeração poderia ser um fator a favor dos espaços rurais para atravessar a pandemia; por outro lado, a distância de serviços hospitalares é um fator que joga contra - apenas para citar um exemplo. De todo modo, tais espaços estão interligados e a própria mobilidade urbano-rural (a ida da população mais abastada às casas de campo, por exemplo) ou rural-urbana (como no caso dos atravessadores do setor agroalimentar) explicitam essa relação.

A temática das relações urbano-rurais, atravessa os mais diversos temas, e é, por isso, tão relevante para a ciência geográfica. No entanto, seja no âmbito acadêmico ou no ensino básico (e, sobretudo, no senso comum) ela ainda é permeada de estereótipos, visões segregadoras desses subespaços, situando-os em polos opostos. Acreditamos que é central quebrar esse paradigma já desde a escolarização, encarando o espaço como integrado, e urbano e rural não como uma dicotomia, mas como um mesmo espaço (cada vez mais complexo) sempre interrelacionado - sem que isso enseje em aniquilar as diferenças, mas contribuindo para a diminuição das desigualdades.

Assim, esse artigo retoma ideias apresentadas em outros trabalhos (RUA, 2002, 2011, 2019), aqui conjugadas para tentar apresentar, principalmente aos professores de ensino fundamental e médio, a temática das relações urbanorurais que atravessa os conteúdos trabalhados em sala de aula nos vários momentos da escolarização. O objetivo final é levar aos professores as reflexões aqui explicitadas, tendo como intuito norteador demonstrar a importância dessa temática para aclarar a compreensão do espaço geográfico como produto, meio e condição para a vida humana, como nos ensina Henri Léfèbvre (2008). Produto já que é resultado do trabalho social que nele se realiza (sendo, também, um meio de produção), condição por ser necessário à reprodução da vida. Assim, o espaço será o conceito fundamental para nossa reflexão e perpassará todo este trabalho, no qual se analisa a crescente complexidade das relações entre urbano e rural, a partir, sobretudo, da abordagem das urbanidades no rural. Portanto, deseja-se expor as principais reflexões acerca das relações urbano-rurais em um espaço cuja análise se complexifica. Reiteramos que é cada vez mais necessário romper os estereótipos, as dicotomias e as representações que são efetuadas nos diferentes níveis de ensino, que obscurecem mais do que clarificam a dinâmica da produção do espaço no mundo contemporâneo e como a ciência geográfica pode explicá-la.

Para tal, na primeira seção do texto faz-se um esforço em expor uma reflexão acerca das relações urbano-rurais na contemporaneidade, apresentando a abordagem das urbanidades no rural como uma possibilidade de superar a visão dicotômica que recai sobre os espaços urbano e rurais. Em seguida, apresentamos provocações ao leitor a partir 
do que chamamos de "momentos". São quatro momentos de reflexão onde discutimos algumas das questões que estão contidas na discussão sobre as noções de campo e cidade, rural e urbano e suas relações, problematizando-as: os estereótipos que envolvem tais ideias, a ressignificação da natureza e sua relação com estes espaços, o papel dos sujeitos sociais na sua produção e, por fim, as armadilhas espaciais tão presentes nas formas de representá-los.

Não se tem o intuito de produzir um material didático para ser diretamente levado para os alunos, ou uma "cartilha" de como produzi-los. Pretende-se, isso sim, proporcionar momentos de reflexão/revisão de conhecimentos adquiridos na universidade e, numa segunda seção, propor "portas de entrada" (ou provocações) para fomentar reflexões em sala de aula, nas escolas, alimentando um diálogo entre nós, professores.

\section{RETOMANDO AS RELAÇÕES URBANO-RURAIS NA PERSPECTIVA DAS URBANIDADES NO RURAL}

Como discutimos em Simoni (2019)², os debates acerca das muitas noções que buscam dar conta das diversas "realidades espaciais" (como urbano e rural) superam a esfera epistemológica e acadêmica a partir do momento em que endossam, por um lado, as "políticas de desenvolvimento" para estes lugares, por outro, as (re)significações pelas quais passam, constantemente, estes termos. Traça-se, assim, a importância do debate conceitual, pois, "as palavras do léxico político sinalizam, através de suas polissemias, usos antagonistas que diferentes grupos dela fazem ou fizerem" (VAINER, 1993, p. 566, apoiado em Bourdieu, 1984³). Como não poderia deixar de ser, são múltiplos os sentidos atribuídos ao campo-rural - seja da perspectiva de suas construções conceituais, seja de suas representações pela e na sociedade moderna.

À luz da sociologia rural, Carneiro (2008) avalia duas vertentes que analisam o urbano e o rural. A primeira, que se baliza sobretudo na sociologia de tradição urbana industrial (americana e alemã), propõe uma dualidade entre essas duas realidades: o urbano enquanto polo da civilização, berço do progresso e da modernidade, ao passo em que o rural constituiria polo oposto - estigmatizado enquanto atrasado, tradicional e estagnado. A segunda vertente de análise, também estigmatizada, propõe o contrário: o rural seria valorizado exatamente pela sua condição de não-cidade, posto que esta seria carregada de males (violência, criminalidade, desvio) (CARNEIRO, 2008). O meio rural, portanto, seria apreciado e analisado por estar "protegido" ou "intocado" desses e de tantos outros males atrelados à cidade, que passa a ser "representada como uma ameaça constante ao meio rural, submetida passivamente à força destruidora dos valores da sociedade de consumo e à ação homogeneizadora da cultura de massa" (CARNEIRO, 2008). A mesma autora irá discutir a presença do rural enquanto uma categoria do pensamento, advogando que a noção de rural, portanto, classificaria e organizaria o mundo social, orientando suas ações.

\footnotetext{
${ }^{2}$ Alguns debates desenvolvidos neste artigo são retomados a partir de trabalho anterior (SIMONI, 2019).

${ }^{3}$ BOURDIEU, P. Espace Social et genèse des 'classes'. Actes de la Recherche em Sciences Sociales. n. 52-53, juin. 1984.
} 
Nesta primeira classificação, pode-se notar como urbano e rural configuram realidades internamente homogêneas, mas em oposição. Em outras palavras, ressaltam-se suas características a partir de sua polarização e de uma valoração do que seria um espaço, a priori, bom ou ruim, moderno ou atrasado, protegido ou degradado. Para que tal análise pudesse se consubstanciar, campo e cidade, rural e urbano, representam-se enquanto totalidades em si mesmas, o que exigiria fronteiras (territoriais e analíticas) claras e rígidas.

Neste sentido, emerge uma importante corrente de análise do rural, desenvolvida, principalmente, no campo da antropologia e sociologia rural. Trata-se da abordagem de que haveria a emergência de "novas ruralidades". Esta vertente enfatiza as transformações nos espaços rurais, sob a ótica de que não vivenciamos um processo de conversão de espaços rurais em urbanos, ou de espaços agrícolas em industriais. No entanto, admite-se uma transformação (em maior ou menor grau) nos espaços rurais, seja do ponto de vista do abandono da prática da agricultura como atividade laboral fundamental, seja do ponto de vista da diversificação das fontes de rendimento, mantendo-se a atividade agrícola como fonte principal.

Por meio desta abordagem, busca-se exaltar a permanência das diferenças dos espaços rurais em relação àqueles urbanos. Conforme Wanderley (2000) estas permanências estão “contextualizadas por processos históricos de reelaboração contínua da dualidade campo-cidade engendrando em novas ruralidades". No entanto, a ideia de permanência não sugere a ideia de imobilidade, de modo que, na perspectiva da autora, “o 'rural' não se constitui como uma essência, imutável, que poderia ser encontrada em cada sociedade. Ao contrário, esta é uma categoria histórica, que se transforma".

Carneiro (2008), ao se debruçar sobre a proposição das novas ruralidades, provoca: seria este "um novo olhar informado por outras lentes que permitiram enxergar - sobre uma variedade de espaços socialmente habitados - uma realidade dinâmica, mutável e com plasticidade que até então era definidora da urbanidade?”

Sem desconsiderar as importantes contribuições apresentadas pelas autoras acima referidas, numa perspectiva geográfica, deve ser destacada a integralidade do espaço. Este será percebido como totalidade, na qual as distintas partes, a um só tempo, constituem particularidades e singularidades seja nas áreas denominadas cidades, seja naquelas consideradas como campo.

Para nós, constituem-se (cidade e campo) com formas, nas quais a construção de objetos difere em quantidade/densidade e, também, os fluxos se realizam com intensidade diversa.

Não existiria, para o desconforto dos geógrafos, uma nítida divisão entre cidade e campo, na qual se enfatizariam as distinções formais; também, para desconforto dos sociólogos e antropólogos não existiriam essencialidades que, em si mesmas, distinguissem cidade e campo. Esses desconfortos estarão presentes no trabalho cotidiano do professor de Geografia, quando necessita construir, com seus alunos, as noções/conceitos acima apontados. Como definir cidade, como definir campo? Como romper com os estereótipos já tão solidificados de que a cidade representa o progresso, 
contém indústria e o comércio e demais serviços, enquanto o campo permanece agrícola, "atrasado" e "estagnado"? Essa distinção é extremamente fácil de ser construída porque já está enraizada nas informações que boa parte dos alunos (e até alguns livros didáticos) carregam para a escola. Percebe-se, desde logo, a necessidade de problematizar tal simplificação. Como se pode explicar um campo do agronegócio (com indústrias, serviços, comunicações variadas) relacionando-o ao atraso e à estagnação? Como explicar algumas partes da cidade obsoletas, "decadentes", favelas, todas com precariedades de serviços e de comunicações? Mesmo estando nas cidades parece difícil considerá-las como "áreas de progresso", de "dinamização" e de "desenvolvimento".

Tentamos demonstrar com esses exemplos que não haveria distinções essenciais entre cidade e campo além daquelas produto das espaço-temporalidades de cada uma dessas partes do espaço. A história das cidades resulta em geografias distintas quando se constrói uma cidade comercial que, posteriormente, é incorporada pela cidade industrial e, mais tarde, todas são integradas nas cidades dos serviços. Não é necessário lembrar os graus e a natureza das diferenças entre uma pequena cidade, uma cidade média e uma metrópole.

Da mesma maneira, o campo/os campos evidenciam enorme diversidade. Como comparar um campo agrícola, policultor, apoiado no trabalho familiar, com um campo da grande monocultura canavieira, apoiado na mecanização e no trabalho sazonal? Essas indagações, dentre muitas outras que podem ser efetuadas, conduzem-nos a pensar o espaço como uma espaço-temporalidade na qual a História e a Geografia vão se mesclando num produto integrador de tantas distinções. De um lado, aqueles atributos que pareciam ser exclusivos da cidade (comércio, indústrias, serviços em geral) distribuem-se por todo o espaço, embora com densidades e intensidades do uso por vezes bastante distintos. Por outro lado, nas cidades (até mesmo nas metrópoles) descobrem-se atributos estereotipados como definidores do campo (agricultura, bosques, vida comunitária). Complexificou-se o espaço e "borraram-se" os limites retirando a todos os estudiosos de suas respectivas zonas de conforto.

Diante dessas dificuldades, preferiu-se utilizar os termos "urbano" e "rural" percebendo-os como evidências de processos de difusão e de interconexão, nos quais a cidade torna-se apenas um ponto de partida para a expansão dos modos de vida, das maneiras de produzir e das normas de consumo; isto é, generaliza-se uma racionalidade urbana que alcança todo o espaço, permitindo-nos falar de uma urbanização planetária em acordo com Léfèbvre (1999). Nessa expansão da racionalidade urbana, o rural transforma-se, mas sem perder muitas das características que lhe são peculiares. Pode-se perceber distintos momentos nessa interconexão. Em primeiro lugar, existirão lugares rurais menos atingidos pela pelas transformações decorrentes da interação com o urbano. Outros lugares serão mais intensamente atingidos, e, com isso, mais intensamente transformados. Ainda deve ser ressaltado que esse movimento de difusão do urbano sobre o rural não se dá em forma de mancha de óleo, pois poderão existir interstícios espaciais pouco transformados em localizações definidas por uma intensa modificação.

A escala vai permitir compreender melhor esse movimento. Na escala geral do espaço verifica-se a aludida difusão do fenômeno urbano (planetário), carregando a lógica do valor de troca e da mercadificação para o todo o globo. Em 
escalas mais aproximadas percebem-se espacialidades muito contraditórias, fruto das maneiras como os sujeitos que vivem nessas áreas recebem a influência do urbano. Com isso, pretende-se explicitar que, com o auxílio da escala, podem ser percebidos distintos movimentos contraditórios que acontecem nas diversas partes do globo (ou do Brasil, ou do estado do Rio de Janeiro, ou da Amazônia...), as quais definirão padrões particulares de interações urbano-rurais, evidenciadas por aquilo que, há muito tempo, vem sendo denominadas "urbanidades no rural”.

A concepção de urbano demonstrada por Léfèbvre fundamenta tal noção, a qual visa a realçar a relação assimétrica entre o urbano e o rural, confirmando a integração - pois a assimetria evidencia relações (de poder, comerciais, culturais), num movimento de permanente hibridização. Assim, "as "urbanidades" decorrentes dessa interação, não serão apenas novas ruralidades, e sim, o urbano presente no campo, sem que cada espacialidade perca suas marcas" (RUA, 2006, p.95).

Assim, para desenvolver a noção de urbanidades no rural ${ }^{4}$, partiu-se de discussões que vão desde a contextualização da Geografia na modernidade, das diversas dicotomias que foram sendo construídas ao longo dos últimos séculos e da percepção de que aquela dicotomia cidade-campo, urbano-rural não fazia mais sentido na medida em que os dois subespaços estavam cada vez mais se hibridizando.

As ruralidades permanecem, mas hibridizadas com esse urbano, o qual as subsome e transforma, numa mescla de tecido cada vez mais intrincado. Por outro lado, como já discutido acima, alguns aspectos que antes marcavam apenas as áreas tidas como rurais, passaram a estar presentes também nas áreas urbanas - por exemplo, a vida em condomínios retoma valores antes atribuídos a áreas rurais (a sociabilidade, as relações de vizinhança, a valorização do verde). Nesse sentido, ao refletir sobre essa totalidade (urbano+rural), Alencar e Moreira (2005) destacam o rural como espaço a ser apropriado, como forma de vida ou modelo alternativo de sociedade pregados pelos movimentos ecologistas, atribuindo novos significados à natureza. Evidencia-se, sinteticamente, em nosso ponto de vista, a ideia de urbanidades no rural, já que apresentam uma outra dimensão da difusão da racionalidade (modo de viver, produzir, pensar e agir) que antes marcava apenas as cidades.

Considera-se que as urbanidades podem ser constituídas por uma enorme gama de manifestações, que incluem aspectos materiais e imateriais. Subentende-se, também, que estas manifestações são evidências da multidimensionalidade do espaço ${ }^{5}$, ou seja, expressam-se a partir de múltiplas dimensões. Torna-se relevante ressaltar

\footnotetext{
${ }^{4}$ A construção dessa perspectiva deu-se através da observação e análise, ao longo de décadas, por parte do autor deste artigo, de processos espaciais e situações geográficas concretas, as quais se iniciaram com turmas de alunos do ensino médio do Colégio de Aplicação da UFRJ, com alunos de graduação do departamento de Geografia (atualmente Geografia e Meio Ambiente) da PUC-Rio, com turmas de alunos do departamento de Geografia da UERJ (Maracanã) e com grupos de pesquisa na UERJ e na PUC-Rio No NEGEF (Núcleo de Estudos de Geografia Fluminense), o qual, juntamente com o Prof. Gláucio Marafon, foi fundado e coordenado, por mais de dez anos, por este autor, essa experiência integrou-se a diversos projetos de pesquisa. Nesse Núcleo é que foram amadurecidas as ideias que vêm alimentando a reflexão, desenvolvida na PUC-Rio desde 2006 e continuada, desde 2011 , no URAIS (Núcleo de Estudos Urbanos e Rurais) do Departamento de Geografia e Meio Ambiente, onde vem se desenvolvendo sucessivas investigações até os dias atuais.
}

${ }^{5}$ Em trabalho anterior (RUA, 2019), explicitou-se que, ao se referir à multidimensionalidade do espaço, consideram-se as dimensões do físico-natural, o econômico, o social, o cultural, o ideológico, o institucional e o pessoal ligados ao cotidiano, de acordo com Milton Santos. 
que essas dimensões só aparecem separadas como recurso expositivo, pois estarão sempre integradas. Ao se tomar cada uma das dimensões apontadas ou os elementos que as constituem (estes também podendo estar incluídos em mais de uma dimensão), procura-se, apenas, um ponto inicial (nuclear) para tal reflexão. Assim, apresentamos, de forma bastante sucinta, alguns elementos - manifestações materiais e imateriais das urbanidades no rural - organizados de acordo com as múltiplas dimensões do espaço (que não se esgotam nas sistematizadas a seguir):

a) de ordem físico-natural: o sítio no qual a localidade está construída ou onde as atividades rurais são realizadas (aspectos físico-naturais, aspectos geomorfológicos e climáticos - carreamento de solos, deslizamentos, enchentes, etc.).

b) de ordem simbólico-cultural: memória coletiva e valorização da tradição, existência (ou não) de um localismo "conservador", convivência com o turismo rural e o veraneio, autoestima, relação com a natureza em seus aspectos imateriais, as percepções ecológico-ambientais e relações mais efetivas com os territórios da vida (populações indígenas, quilombolas, camponeses, etc.).

c) de ordem socioeconômica: dominação capitalista do espaço, conflitos entre o valor de uso e o valor de troca, renda territorial e preço da terra, importância da propriedade da terra (privada, pública ou comunitária), renda gerada pelo turismo, criação de novos empregos, presença de indústrias (ligadas ou não à produção agrícola), assistencialismo oficial e de ONGs, consumo e consumismo, associativismo, participação política e movimentos reivindicatórios.

d) de ordem técnica: adoção de novas tecnologias, inclusive de informação, presença de produtos agrícolas diferenciados, formas de comercialização que integram o lugar a redes mais amplas de raiz metropolitana e internacional, saneamento básico e coleta de lixo, existência de supermercados, estudos sobre a poluição da água e do lençol freático, cuidados no uso de agrotóxicos.

Assim, tais urbanidades constituem, como visto, materialidades e imaterialidades, isto é, um sistema de objetos e um sistema de ações pautadas por intencionalidades dos distintos sujeitos produtores do espaço ao executarem tais ações/materialidades/imaterialidades. Pode parecer estranho colocar-se, por exemplo, o rádio, o celular e serviços a partir da internet (como o Internet Banking e as redes sociais) lado a lado como elementos difusores das urbanidades no rural. Mas é preciso recordar as diferenças do espaço planetário e as desigualdades na vivência das múltiplas escalas. Como mensurar a importância do rádio na alteração dos modos de vida de uma família camponesa que disponha apenas desse meio de comunicação? Muito próximo desse rádio, podem situar-se outras maneiras de integrar as escalas da vida. Serão sujeitos desigualmente e diferentemente voltados para o mundo.

Portanto, ao vivenciarem essas urbanidades, os moradores de lugares rurais passam a participar de relações bastante contraditórias, pois da matriz da modernidade ocidental da qual procede o discurso da urbanidade, dos direitos do cidadão e do "homem", procedem, simultaneamente, as matrizes tanto dos processos de dominação (ligados à 
propriedade privada e às hierarquizações desigualizadoras referentes ao capitalismo) quanto os de autonomia individual e coletiva, as quais podem apontar para outras maneiras de organização social e espacial distintas das hegemônicas ${ }^{6}$.

Tais reflexões tencionam as simplificações ainda predominantes nas discussões pertinentes às relações urbanorurais, majoritárias no ensino fundamental e médio e nos livros didáticos de Geografia. É preciso destacar a busca pela superação dessa visão tradicional efetuada tanto por muitos professores em sala de aula, quanto por diversos autores de livros. Partilhando esse movimento de desvendamento das dicotomias, colocamo-nos também como professores ao procurar sugerir elementos para alimentar a necessária reflexão na prática docente do ensino fundamental e médio. Estas ideias serão desenvolvidas na próxima seção deste texto, onde apresentam-se algumas contribuições das noções (e seus desdobramentos) para o ensino de Geografia e, em específico, de Geografia Rural, dentro de uma perspectiva do espaço (e da Geografia) como totalização, isto é, sempre em movimento - uma totalidade que não se completa.

Refletindo sobre relações urbano-rurais no ensino escolar: algumas provocações

Esta seção do texto, conforme já apontado, tem o objetivo de apresentar algumas provocações acerca de diferentes temáticas ou questões associadas às relações urbano-rurais e à abordagem de urbanidades no rural. $\mathrm{A}$ reflexão será conduzida através de momentos que inspirem perspectivas de desdobramentos para que se trabalhe com os alunos. É importante destacar que esses momentos buscarão entrecruzar elementos constantes no texto acima, sejam aspectos teóricos ou mais objetivos.

\section{1ㅇ momento: Procurando romper estereótipos que ainda marcam as relações urbano-rurais}

Uma primeira ideia que aparece bastante cristalizada em nossa sociedade é a de que a cidade é rica e o campo é pobre; o urbano é progresso e o rural é atraso. Como romper esses estereótipos? Escrevemos no texto acima que rural e urbano constituem um espaço único, no qual os "atributos" rurais e urbanos estão distribuídos desigualmente. Há favelas urbanas e há favelas rurais. Há bairros de classe alta na cidade, mas também no campo.

Talvez o conceito geográfico de paisagem ajude a romper esses estereótipos quando se consideram esses elementos simbólicos, culturais e subjetivos, isto é, um espaço representado (HAESBAERT, 2014). Se apresentarmos fotografias, pequenos filmes ou outras imagens que ao mesmo tempo contrastem uma favela de uma metrópole com um complexo do agronegócio no Brasil central, onde está a pobreza? Por outro lado, os contrastes pobreza-riqueza devem ser evidenciados tanto na cidade como no campo.

Nos anos finais da escolarização, pode-se trabalhar com as desigualdades sociais espacializadas como característica fundamental do capitalismo: a segregação socioespacial no campo e/ou na cidade.

${ }^{6}$ Para aqueles que desejarem maior aprofundamento no estudo desta temática, sugerem-se as leituras RUA (2019; 2020). 
Desde muito tempo, quando ainda parecia fazer sentido trabalhar-se com setores da economia - primário, secundário, terciário - já se lidava com sérios problemas de distinção, definição e localização desses setores. Parecia claro que o setor primário (agricultura, extrativismo, pesca) correspondia às áreas rurais, enquanto os setores secundário e terciário estariam localizados em áreas urbanas. Na medida em que os fluxos de mercadorias, de pessoas e informações integravam cada vez mais urbano e rural, evidenciaram-se problemáticas até hoje pouco abordadas. Como explicar indústrias ligadas, ou não, à agricultura em áreas rurais e como explicar serviços ligados ao turismo, educação, saúde, comércio também nelas localizadas? A explicação pode ser composta tendo como ideia básica a multidimensionalidade do espaço. O social, o político, o econômico, o técnico e a própria localização física dos empreendimentos agroindustriais, de condomínios de luxo, de hotéis-fazenda podem representar a complexidade de elementos que compõem o espaço geográfico.

E como se coloca, nesse contexto, a autoidentificação das pessoas que produzem essas espacialidades complexas? Como se veem os empresários, os proprietários rurais, os trabalhadores rurais nessa perspectiva de espaço como totalidade? Constituem-se como sujeitos sociais e políticos fundamentais na fricção provocada pelas assimetrias de poder.

Essa problemática da autoidentificação entrecruza-se com a da composição da renda familiar. Se até décadas atrás a atividade agrícola organizada e conduzida pelo chefe da família constituía-se na base de sustentação familiar, mas recentemente essa composição da renda diversificou-se, fragmentando de certo modo o papel que cada membro da família representa nesse grupo. O chefe da família pode trabalhar na agricultura e, nos fins de semana como jardineiro num condomínio rural próximo; a esposa, além da lida doméstica e de auxílio na plantação, ainda complementa a renda familiar como diarista em hotéis, condomínios ou fazendas das vizinhanças; a filha trabalha num supermercado; o filho é empregado numa oficina mecânica. Observa-se, nesse exemplo, que na composição da renda familiar pesam mais as atividades não-agrícolas do que aquelas diretamente vinculadas à produção. Não se trata apenas de aspectos econômicos (renda, produção agrícola, empregos diversificados) mas, também, de aspectos sociais e simbólicos, os quais retroagem sobre a autoidentificação, sobre as relações familiares e sobre o domínio patriarcal tradicional, para dar apenas alguns exemplos. Aí podem ser evidenciadas também questões de gênero, nas quais é preciso destacar a relevância adquirida e reconhecida para o novo papel da mulher na sociedade. Esses fatos, novamente, confirmam a integralidade do espaço já que se apresentam tanto em áreas rurais como urbanas.

Estereótipo ainda bastante difundido é o de que no rural se vive "na roça": todos sabem da vida de todos, há forte controle social, pouca liberdade de ação e de expressão individual e domínio das relações comunitárias; o rural como lugar da paz e da tranquilidade (não violência) - uma visão idílica de rural.

Essas características ficavam acopladas à ideia de campo atrasado e cidade avançada, pois que nesta se viveria a individualidade, a plena liberdade e a privacidade. Como ficam tais situações nos dias atuais? Em muitas áreas rurais observa-se a crescente presença de condomínios (forma de vida comunitária bastante distinta da tradicional); os meios 
de informação estão disseminados em, praticamente, todos os lugares (rádio, televisão, internet); nas áreas urbanas valoriza-se, cada vez mais, o verde, produtos "da roça”, a vida em condomínios fechados, formando comunidades que procuram valorizar atributos antes vigentes nas áreas rurais. Alguns autores (ALENCAR; MOREIRA, 2005) chegam a falar em campo e cidade metropolitanos. O próprio individualismo e a vida libertária antes atribuídos apenas às cidades, também se generalizam. Quanto à violência e a não violência, o que dizer dos conflitos permanentes pela posse da terra, a forte presença do tráfico de drogas e do crime organizado tanto em áreas rurais como em áreas urbanas? Por vezes a intensidade parece ser distinta, mas e se pensarmos na densidade populacional?

Finalmente retorna-se à paisagem, em que o rural e o agrícola devem ser distinguidos. $\mathrm{O}$ agrícola evidenciando uma paisagem de produção enquanto o rural apresenta-se como paisagem mais complexa, contendo atividades agrícolas, industriais e de serviços. Podemos, então, observar vários estereótipos, os quais estão sendo estressados pela forte tendência à integração do espaço. Aqui evidenciaram-se apenas alguns dos muitos estereótipos que marcam as visões de rural, urbano, agrícola, natureza e que colocamos como provocações que possam desafiar o diálogo entre professores e alunos. Percebem-se, também, diversas manifestações de urbanidades no rural, tanto de caráter material (o sítio de localização, a presença de meios de comunicação, condomínios de luxo), quanto imaterial (novos valores, costumes, transformação no papel da mulher), dentre muitas outras evidenciadas.

\section{0- momento: Ressignificando a natureza nos estudos das relações urbano-rurais}

Uma visão ainda marcante nos estudos geográficos é aquela relacionando a paisagem natural ao espaço rural: o verde e as florestas sendo percebidos como atributos de áreas rurais. Isso parece extremamente lógico e fácil de aceitar; afinal de contas florestas e ambientes urbanos parecem não combinar. Ao mesmo tempo, a ideia de natureza relacionada às áreas rurais também pode ser identificada com atraso, rude, selvagem e recurso a ser transformado. Essa identificação reforça estereótipos que vêm marcando a civilização ocidental na modernidade. Se a ideia de urbanidade foi cunhada nesse período histórico, também aí se localiza a fissura entre natureza e o homem. A natureza vista como obstáculo a ser removido - os bosques e florestas transformados em plantações, os rios transformados em canais de navegação e de irrigação - para a plena realização da lógica produtiva. Por séculos, essa perspectiva predominou. E, de certa maneira, ainda predomina. Basta observar os grandes incêndios florestais intencionais levados a cabo nas áreas florestais brasileiras, reduzindo-as cada vez mais. Tal exemplo de destruição elucida bem a compreensão da natureza como objeto/recurso/obstáculo à expansão da grande lavoura/pecuária e de grandes projetos minerais ou hidrelétricos.

É interessante ressaltar aí que dois movimentos paralelos se desenvolvem contrariando essa visão utilitarista da natureza. O primeiro projeto parte do discurso conservacionista fortalecido nos movimentos sociais de base ecológica. Conservar e preservar passam a fazer parte integrante de políticas públicas mais efetivas em uns países que em outros e mais representativas em alguns períodos da história recente. A esses movimentos deve-se a demarcação e proteção de numerosas áreas florestais, campestres e de restingas. O segundo projeto parte de uma efetiva valorização e precificação de áreas verdes em geral. Fala-se em mercadificação da natureza na qual a vista para o verde, usufruto do ar mais puro, 
mas também, o preço/valor das madeiras plantadas passam a ser atributos levados em consideração pelo capital e pelas formas diversas de obtenção do lucro.

Esses dois projetos podem ser reunidos em um rótulo bastante difundido como "ressignificação da natureza". Qual ressignificação, do verde como valor para vida ou do verde como mercadoria? Como distingui-los em áreas circundantes aos parques naturais protegidos pela ação de movimentos ambientalistas mas que são incorporados como valor agregado a hotéis, pousadas, condomínios rurais? Alguns autores chegam a falar em parques e reservas naturais como áreas de expansão futura do capital. Pode parecer estranho, mas nada garante que a legislação protecionista de hoje permaneça. Karina Bernini (2019), refere-se a isso da seguinte maneira:

Fica evidente que o caráter preservacionista que foi assumindo a política de conservação decorre da expansão da lógica da propriedade privada que, ao estabelecer as relações de produção capitalistas, parcelando e mercantilizando a terra para implantar projetos agropecuários e de infraestrutura, define também as áreas que deveriam permanecer isoladas desse uso. É nesse sentido que podemos afirmar que a necessidade de conservação ambiental se impõe como parte da forma como a natureza vai sendo apropriada pelo processo produtivo capitalista. $E$ a definição de unidades de conservação se processa no contexto em que a terra se torna mercadoria, portanto, a destinação para conservação ambiental acontece a partir da apreensão dessa "primeira natureza" pela lógica do mercado (p. 671).

Nesse sentido, como deixar de denunciar as crescentes violações da legislação protecionista em proveito da expansão de áreas para a agricultura, para a pecuária, para loteamentos em áreas rurais, ou como resultados de grilagem e açambarcamento de terras, tal como se percebe nas (re)discussões sobre o código florestal brasileiro? Outro aspecto relevante prende-se às distintas relações das técnicas com a natureza/meio geográfico. Técnicas qualquer produtor ou pecuarista possui. Uma visão de natureza e de como com ela lidar, também. No entanto, a relação agricultor/produtor rural com aquilo que genericamente estamos chamando de natureza, varia de acordo com o padrão socioeconômico a eles relacionados. É preciso distinguir os efeitos de uma queimada de pequena área voltada à produção agropecuária de uma grande queimada destinada à destruição da floresta, com a intenção de substituí-la por pastagens ou monoculturas. Todas constituem-se em queimadas, mas uma (a primeira) integra-se a um sistema produtivo que permite a reconstituição da mata ao fim de alguns anos. A segunda procurará utilizar predatoriamente aquela área voltada para a grande produção e, ao passar do tempo, com a produtividade em declínio e a terra exigindo doses maciças de fertilizantes, o gradativo encarecimento da produção "empurra" esse fazendeiro para novas áreas deixando as anteriores ao abandono. A aliança agricultor familiar/camponês com a preservação da natureza constitui-se em prática costumeira.

Entretanto, essas práticas costumeiras ficam abaladas com a crescente integração da produção familiar camponesa aos "pacotes técnicos", instigados pelo mercado (padronização da produção), os quais induzem outras concepções de natureza que não aquelas cultivadas na tradição desses produtores. A noção de natureza a partir da ciência convencional e da técnica moderna fragilizam em muito as relações que os denominados povos tradicionais e os 
agricultores familiares integrados ao mercado têm entre si e com o meio geográfico que produzem e do qual fazem parte. Tal fragilidade se explica pela supremacia que a ciência moderna apresenta em relação aos saberes tradicionais. Estes, muitas vezes, ficam subjugados ao conhecimento científico que vai tornar-se uma das mais representativas urbanidades difundidas nas áreas rurais. 0 menosprezo pelos saberes tradicionais torna-se tão devastador quanto o menosprezo pela floresta e pela vida que ela contém, levado a cabo por ataques a elas dirigidos pelos grandes empreendimentos ou pelas ocupações ilegais (grilagem, garimpagem, extrativismo clandestino...).

Como evidência da relação técnico-uso do solo-destruição da natureza, podemos pensar em dois exemplos: o primeiro na região serrana fluminense localizado num interflúvio com solos bastante desgastados após desmatamentos sucessivos impõe ao agricultor familiar um padrão técnico baseado na utilização intensiva de agroquímicos. Nesse padrão (pautado por técnicas modernas ligadas à revolução verde) resultam várias situações que merecem uma reflexão específica. O princípio da padronização da produção faz com que o agricultor obedeça a tamanhos particulares para cada produto, em acordo com as normas de encaixotamento; o intenso uso de agroquímicos polui os solos, polui as águas nos rios e mananciais e afeta a saúde do agricultor; nas próprias localidades rurais o lençol freático fica comprometido e torna-se mais um fator de insalubridade. Nesse exemplo constata-se, também, a intensa relação com o mercado e com a visão utilitarista de natureza.

Outro exemplo pode ser lembrado em uma fazenda de soja no estado do Mato Grosso, num sítio planáltico (plano) propício à intensa mecanização e ao profundo revolvimento do solo. Aí podem ser percebidos muitos dos efeitos deterioradores da relação sociedade-natureza apresentados neste momento de reflexão. $O$ solo fragilizado pela retirada da floresta e da matéria orgânica dela resultante é rapidamente esterilizado pela monocultura, pela lixiviação e pelo intenso uso de agroquímicos. O resultado virá manifestado de diversas maneiras: o abandono dessa terra após alguns anos de uso; o envenenamento do solo, do lençol freático e dos rios que por ali passem, os quais vão contaminar águas de localidades distantes, muitas vezes, até de parques protegidos e de terras indígenas que têm, assim, sua sobrevivência ameaçada.

Esses exemplos servem para nos mostrar a importância de se compreender as relações sociedade-natureza (esta transformada em meio geográfico); para demonstrar a importância dos elementos ligados ao "quadro natural", o qual servirá de base material para a produção; servem, também, para repensar os efeitos do "pacote técnico moderno" apresentado aos agricultores como superior às formas tradicionais de produzir.

Nesse momento de reflexão sobre a ressignificação da natureza, podemos entrecruzar diversos elementos constitutivos das distintas dimensões representantes de diferentes urbanidades no rural, os quais podem ser transformados em exercícios com os alunos, promovendo mesclagens de elementos de cada uma das dimensões (natural, simbólico-cultural, socioeconômica e técnica). 
3o momento: (Re)conhecendo os sujeitos sociais produtores do espaço e sua importância nas transformaç̃̃es ocorridas nas relações urbano-rurais

Uma maneira que parece interessante para abordar a problemática que relaciona os sujeitos sociais com as espacialidades por eles vividas, pode ser sintetizada em alguns pontos que serão elencados neste momento de reflexão com os professores:

1) Por que se torna necessário distinguir a ideia de urbanização do rural daquela que apresenta a urbanização no rural?

Urbanização do rural significaria a urbanização física (formas construídas) estendida a todas as áreas rurais. Mesmo que isso ocorra em áreas bem limitadas, próximas às cidades onde, de fato, ocorre tal expansão física sobre antigas áreas rurais, ainda assim, em termos planetários tal fato representa áreas muito restritas. Portanto tal ideia parece pouco provável de tornar-se realidade.

O que defendemos em nossa reflexão sobre as relações urbano-rurais é que ocorre uma generalizada urbanização no rural. Isso significa a presença do fenômeno urbano difundida pelo espaço rural. A qual fenômeno urbano estamos nos referindo? A um urbano ideológico e comportamental, no qual hábitos e costumes urbanos tornam-se presentes no espaço rural, com maior ou menor intensidade, conforme já discutido na primeira seção deste artigo. Também como já visto anteriormente, à difusão dessa racionalidade urbana é que denominamos urbanidades no rural, as quais abrangem materialidades e imaterialidades nos seus elementos componentes. A presença de técnicas sofisticadas, do crédito rural, dos meios de comunicação diversificados, do tempo do relógio (a cronometragem da vida cotidiana rural a qual deixa de ser marcada pelo sol), os celulares, a televisão ou até somente o rádio já podem significar mudanças de tais hábitos e costumes.

Parece-nos interessante mostrar aos alunos essa gradação, pois, mesmo quando só se tem acesso a um simples rádio ou ao celular, hoje tão difundido, aí já estará presente a lógica urbana nas múltiplas leituras locais às quais está submetida.

\section{2) Quem são os sujeitos envolvidos com a produção do espaço rural?}

Podemos lembrar alguns: proprietários, não-proprietários; arrendatários, meeiros, moradores em aglomerados rurais, trabalhadores rurais que moram nas cidades, Estado, empresas... Mas como cada um desses sujeitos desenvolve suas práticas espaciais? É preciso destacar as relações de poder muito desiguais (assimétricas) que atravessam, interconectando, tais práticas. Por exemplo: a ação do estado com políticas públicas voltadas para a eletrificação rural, abertura e conservação de vias de comunicação, atuação nas áreas de saúde e de educação (presença de escolas e de postos de saúde) pode afetar a atuação de meeiros, pequenos proprietários, ou grandes produtores de monoculturas. A importância da estrada para o escoamento da produção é bastante distinta para produtores proprietários e 
empregados rurais; o fato de morar na cidade e trabalhar em atividades rurais pode, num período de entressafra, colocar esses trabalhadores disponíveis para o mercado de trabalho urbano; o acesso à escolaridade pode tornar-se um elemento de homogeneização de hábitos e de difusão da racionalidade urbana já que, em muitos casos, as escolas em áreas rurais seguem os mesmos currículos e utilizam o mesmo material didático daquelas em áreas urbanas. Com esses exemplos pretende-se demonstrar a relevância das assimetrias de poder e das escalas de ação desses atores e agentes produtores de espaço. Um grande proprietário voltado para o agronegócio, tem sua vida pautada pelas oscilações do mercado nacional e internacional, vivenciando, assim, múltiplas escalas que vão da local (onde reside e produz) até a global (da qual sofre as determinações para o rumo da sua atividade). Já um meeiro que habite no local de trabalho ou próximo dele vivencia pequena escalaridade em sua vida cotidiana, ficando restrito à curta relação casa-trabalho e dela saindo apenas através dos parcos meios de comunicação que possua.

A apresentação dessa pluralidade de sujeitos produtores do espaço rural deve constar na escolarização desde o ensino fundamental. As relações contraditórias (por exemplo, a desigualdade na vivência das escalas espaciais) devem, também no ensino escolar, ser apontadas e problematizadas. Sobre esse ponto, nos debruçaremos no tópico a seguir.

3) Como é vivida (desigualmente) a multiescalaridade da vida no lugar rural?

Pensamos ser necessário ressaltar o papel da escala da ação na vida cotidiana para evidenciá-la como mais um elemento desigualizador social e espacialmente. É claro que se trata de uma escala de atuação, de seleção, dos fenômenos da vida cotidiana e não da escala cartográfica que frequentemente utilizamos e na qual muitas vezes ficamos aprisionados.

As profundas transformações multiescalares, resultado de processos complexos globais (industrialização, urbanização, reestruturação produtiva no sentido mais amplo), não se traduziram em nenhuma forma de igualização espacial que provocasse o desaparecimento das particularidades do rural, mas redefiniram as relações cidade/campo e urbano/rurais, o lugar do agricultor e da agricultura na sociedade, a importância econômica, social, cultural e política dos atores locais (rurais) no jogo de negociação assimétrica que, permanentemente reconstrói o lugar e as territorialidades que nele se explicitam.

A seguir, apresentamos quatro trechos de trabalhos elaborados com a intenção de refletir sobre a importância desses pontos acima elencados.

O primeiro, relata apontamentos da pesquisa de Agueda (2019, p. 220) que, ao estudar as urbanidades em dois bairros rurais de distintos municípios da Região Serrana do Rio de Janeiro (Nova Friburgo e Teresópolis), assinala que:

são percebidas mudanças relacionadas tanto a aspectos materiais como imateriais. Se por um lado, são verificados nas localidades estudadas novos serviços, o estabelecimento de grandes empreendimentos, como condomínios de alto padrão, e um aumento do preço da terra associado a 
eles, por outro, percebemos transformações nas práticas sociais, na formação de novos valores identitários e nas representações acerca daquele espaço. Os aspectos materiais e imateriais mesclamse na construção de novas espacialidades, híbridas, resultantes da relação dialética entre integração (pela escala mais ampla da mercadoria e da reificação, pelos códigos urbano-metropolitanos) e ruptura (onde percebemos um espaço essencialmente fragmentado, marcado por um nítido contraste entre as territorialidades impostas pelas representações hegemônicas e as territorialidades referentes aos habitantes locais).

De forma complementar, a pesquisa desenvolvida por Simoni (2019, p. 148) destrincha as urbanidades no rural de localidades rurais também do município de Nova Friburgo, ao apontá-las a partir da presença de unidades de hospedagem da plataforma Airbnb:

A presença da técnica (física e virtual) necessária para a existência e manutenção do modelo do Airbnb, provoca tensões e transformações no espaço. De início, das grandes metrópoles. Mas, com inclinação a globalizar-se, encontra também nas localidades rurais espaços para o consumo. (...) Quando tratamos da presença do Airbnb nessas localidades rurais, traçamos a presença multiescalar do capital; (...) e ressaltamos a relevância da abordagem das urbanidades no rural e, aqui, da relação global-regionallocal na produção destas localidades rurais. A presença desta (e de tantas outras) empresas globais; a prevalência de turistas (e "gerentes") vindos da metrópole do estado; bem como o tipo de amenidades que se busca quando se dirige a este espaço rural exige que ajustemos as lentes para pensar as urbanidades, as ruralidades, as metropolitanidades e globalidades no lugar.

As urbanidades também podem se apresentar através de mecanismos estatais e políticas públicas. Pereira (2019,

p. 40) sinaliza alguns efeitos que podem ser destacados a partir da política de microcrédito rural no Territórios Quilombolas de Oriximiná (PA):

a introdução do microcrédito rural e a formalidade do sistema de crédito na organização coletiva da agricultura familiar é uma problemática que merece uma investigação historiográfica, na medida em que o Pronaf (em suas múltiplas faces) pode ser mais um mecanismo legal de controle da atividade prática, da apropriação territorial, além de poder ser um elemento que fortalecerá a lógica da acumulação individual do excedente e de capital; destoando da organização coletiva do trabalho familiar, das noções de coletividade e cooperação para a segurança alimentar entre as famílias.

O quarto trecho apresenta uma discussão sobre a urbanização de regiões dinamizadas pelo agronegócio em Mato

Grosso nas últimas décadas, ao afirmar que esta:

(...) está articulada ao novo e veloz processo de produção do espaço agrário - vinculado à expansão da fronteira agrícola dos anos 1970, redimensionada pelo agronegócio a partir dos anos 1990-, à atuação patrimonialista do próprio Estado - em suas políticas de planejamento territorial - e aos capitais agroindustriais e financeiros nacionais e internacionais, em sua reprodução geográfica desigual. A expansão das modernas atividades agrícolas nessas regiões tem envolvido a constituição de um novo espaço-tempo marcado por intensas transformações espaciais coordenadas pela lógica da produção de commodities agrícolas (VOLOCKO, 2015, p.41). 
Como se pode notar, esses trechos apresentam distintas realidades do rural brasileiro, evidenciando a um só tempo, as ideias apontadas acima (urbanização no rural, pluralidade de sujeitos sociais, assimetrias de poder, vivência desigualizadora das escalas...) e, ao mesmo tempo, retomando diversas urbanidades no rural e as maneiras como elas se manifestam.

Pode ser percebida, assim, a aludida difusão da racionalidade urbana mencionada na primeira parte deste artigo. Mais uma vez enfatizamos que não se trata apenas de difusão de modos de viver, pensar, agir e produzir portados por tal racionalidade, traduzidos naquilo que denominamos urbanidades no rural e, das quais, apresentamos diversos exemplos. Trata-se, também, de infundir valores e ritmos relacionados ao mercado, à indústria e à financeirização como processos que sustentam as novas espacialidades produzidas pela hibridização/mesclagem do urbano e do rural.

Ora, toda essa complexidade espacial resultante dessa hibridização carrega consigo uma série de efeitos positivos e negativos. A urbanidade burguesa da modernidade ocidental produziu esses valores/ritmos. Esses ao mesmo tempo que portam elementos de dominação ligados à lógica capitalista hegemônica (preço da terra, mecanização, quimificação, tempo do relógio...) portam, também, elementos ligados à liberdade, à participação política, ao papel da mulher na sociedade... Vê-se, assim, como apresentado na primeira parte deste artigo, que ao vivenciarem essas urbanidades, os moradores de lugares rurais passam a participar de relações bastante contraditórias, pois da matriz da modernidade ocidental da qual procede o discurso da urbanidade, procedem, simultaneamente, as matrizes tanto dos processos de dominação quanto os de autonomia individual e coletiva, as quais podem apontar para outras maneiras de organização social e espacial distintas das hegemônicas. Essas outras maneiras apontam para a necessidade de uma visão integral do espaço (aberto, relativo e relacional), rompendo, mais explicitamente, com as tradicionais dicotomias ainda mantidas, como demonstrado ao longo do texto e que devem ser questionadas junto aos alunos.

4o momento - Compreendendo as armadilhas espaciais e territoriais como fatores limitantes para a análise geográfica das relações urbano-rurais

Neste momento, faremos uma reflexão a partir de alguns conceitos da ciência geográfica (espaço e território) e como muitas vezes o seu uso essencialista nos aprisiona, criando verdadeiras armadilhas que nos impedem de interligar permanentemente a parte e o todo. Sobre isso, Haesbaert (2014, p. 32) escreve que: “os conceitos não só não podem ser tratados isoladamente como nunca constituem unidades homogêneas, sempre são múltiplos, tanto no sentido interno, com seus elementos, suas sobreposições e sua flexibilidade em torno de uma problemática ou foco central, quanto no sentido externo, na relação com outros conceitos dentro de uma constelação ou sistema mais amplo permanecendo sempre abertos, portanto, a novas conexões potencialmente realizáveis".

Por exemplo, ao se trabalhar com a Região Metropolitana do Rio de Janeiro, pode-se observar essa simultaneidade do uso de conceitos tais como espaço, território e escala. Em Rua (2017) escreveu-se que: “os limites municipais [da RMRJ] são pouco percebidos pelos seus habitantes. Tal fato se traduz, dentre outras maneiras, pelos 
movimentos pendulares de trabalhadores em seu mercado de trabalho ou na busca por melhor atendimento no setor de saúde, no setor da educação e de outros serviços por parte dos habitantes em geral”. Basta lembrar os constrangimentos à circulação por ocasião da pandemia do coronavírus. Habitantes dos municípios da Baixada Fluminense tinham sua entrada no município do Rio de Janeiro contingenciada a ações e atividades muito pontuais. Ora, estes constrangimentos evidenciam a tentativa de colocar os limites administrativos como containers da vida. Aí percebe-se o espaço absoluto (geometrizado) balizado pela dimensão funcional do território (fronteiras intermunicipais), o aprisionamento dos habitantes a um lugar e a uma escala local. Em outro trecho, Rua (2017), bastante influenciado pelas reflexões de Haesbaert (2014), acerca da contenção e exclusão territorial, demonstra como tais processos são bastante evidentes na metrópole do Rio de Janeiro e em outras áreas do estado, incluindo áreas rurais: "narcotráfico e milícias, grandes projetos de infraestrutura e outras medidas de cunho oficial, além da precificação geral do solo, usado para habitação, trabalho ou lazer, constituem-se em marcantes constrangimentos à permanência ou à circulação das pessoas dentro de seus próprios municípios e entre os municípios da RMRJ e de outras regiões do estado".

Assim, se pensarmos em relações cidade-campo e urbano-rurais, também aí é preciso escapar das armadilhas espaciais/territoriais - veja-se, por exemplo, a ação dos aviões pulverizadores de agrotóxicos, as queimadas em áreas florestais (que chegam a fechar aeroportos) e a poluição industrial. Até onde vão seus efeitos (na saúde humana, nas deseconomiais ambientais...)? Respeitam eles os limites municipais e as divisões entre o que se considera urbano e o que se considera rural?

Há outro aspecto da necessidade de se considerar o espaço como integrado, ainda relacionado à dimensão político-administrativa. Como vimos em Rua (2019), desde o final dos anos 30, o Brasil definiu a cidade como sendo a sede do município. A esse núcleo foram acrescentadas as vilas, sedes dos distritos (divisões do município). Durante muitas décadas, a população urbana foi considerada como sendo a soma dos habitantes das cidades e das vilas. $O$ restante era chamado de população rural. A partir de 1970, o IBGE vem ampliando os núcleos que são considerados urbanos, sempre seguindo indicações das prefeituras. A estas, cabe o direito de definir aquilo que pode ser considerado urbano ou rural. Deve ser ressaltada a importância do IPTU (Imposto Predial Territorial Urbano) que é arrecadado pela Prefeitura. Aquilo que, no município, não for considerado urbano será tributado com o ITR (Imposto Territorial Rural), o qual não é por ela coletado. Portanto, já se vê que há um interesse em "criar" espaços urbanos, pagadores de IPTU, o que demanda frequentes alterações na legislação. Criam-se, assim, situações bastante curiosas, nas quais, por vezes, os moradores de um lado de uma estrada são considerados urbanos (pagando IPTU) e os do outro lado são considerados rurais (pagando ITR). Em que, efetivamente, diferem seus valores e ritmos de vida cotidiana, mesmo que voltados para distinta atividades produtivas, quando isto acontece?

É preciso ressaltar que esse critério de definição daquilo que é urbano e do que é rural é utilizado apenas no Brasil; em outros países há critérios totalmente distintos, o que dificulta a validade das frequentes comparações efetuadas entre os índices de urbanização, muitas vezes, tidos como indicadores de desenvolvimento. 
Neste sentido, Salazar, Hidalgo e Paéz (2011, p. 210), ao analisar o processo que chamam de expansão residencial intrametropolitana em direção às áreas rurais chilenas, propõem um olhar sobre as mudanças nas definições de ruralidades, com foco nos casos da América Latina e Caribe. Pode-se notar, pela sistematização apresentada, que o rural (do ponto de vista formal) é definido de acordo com os seguintes critérios: a) quantidade de habitantes - podendo ser atrelada à disponibilidade de serviços, ou não; b) tamanho do povoamento, em relação à ocupação da população economicamente ativa; c) em contraponto à residência urbana - definidas administrativamente ou pelo censo (o caso do Brasil, como apresentado acima).

Estas definições, adotadas para estratégias de políticas públicas e planejamento territorial, possuem grandes limitações, calcando-se, ainda, no viés dual entre cidade e campo, diferenciados, sobretudo, pelo tamanho da população ou do povoamento; ou, ainda, em uma conceituação por mútua exclusão (rural seria aquilo que não é definido como área urbana). Todos esses critérios mantém a tradicional dicotomia urbano-rural.

Di Cione (2005, p.2) também faz alusão a uma crise epistemológica decorrente do que aqui estamos chamando de armadilhas espaciais - ao nos lembrar que os limites são sempre subjetivos. O autor irá afirmar que esta crise se manifesta em muitos estudos regionais ou representações cartográficas, nas quais "as identidades e fenômenos estudados mantem-se circunscritos aquilo que "observável” interiormente ao espaço formal da geometria, ou seja, à área ou volume circunscritos por limites artificiais" - ao buscar compreender esses fenômenos "internos", sempre será necessário transpor os limites fixados inicialmente.

Retoma-se, aqui, o que foi apresentado na primeira parte desse artigo: não há, para o desconforto dos pesquisadores e professores, uma nítida divisão entre cidade e campo e urbano e rural, na qual se enfatizariam as distinções formais; ou, ainda, essencialidades que, em si mesmas, os distinguissem. Como também apontamos acima, esses desconfortos estarão presentes no trabalho cotidiano do professor de Geografia, ao buscar construir, com seus alunos, tais noções/conceitos.

Se, neste momento, a base teórico-conceitual foi buscada em Haesbaert (2014) - mesmo utilizando-se apenas a dimensão funcional, embora reconhecendo a importância que a dimensão simbólica representa na discussão aqui efetuada - a concepção de espaço foi buscada em Léfèbvre (2008), Harvey (2012), Santos (1985, 1994, 1996) e Massey (2008). As formulações desses autores amparam a consideração de relações urbano-rurais como evidências de um espaço relativo/relacional (contendo, mas ultrapassando, o espaço absoluto, limitado, cartesiano - em diálogo com Di Cione), do espaço como condição para a reprodução social da vida que ocorre nos lugares de modo multiescalar por estarem integrados a sistemas de objetos e de ações levadas a cabo por aqueles que atuam produzindo esse espaço nas distintas e simultâneas escalas que tais ações admitem. 


\section{CONSIDERAÇÕES FINAIS}

A análise parcelar, dicotômica e delimitada tem marcado muitos estudos sobre o espaço geográfico e, também, seu ensino na escola - ambos sempre relacionados. Essa dinâmica fragmentadora marca, também, os diversos recortes temáticos dentro da Geografia - por exemplo, "Geografia Rural”, "Geografia Urbana”. Estes devem ser aceitos por questões didáticas, mas sem perder o foco de que são um recorte da ciência geográfica - e a Geografia deve sempre lidar com o espaço como totalidade ${ }^{7}$. Não se trata apenas do espaço em seu viés operacional, como vimos durante tantos anos (com a máxima de que "a Geografia é a ciência da organização do espaço"). Há cerca de 30 anos, tal ciência é percebida como saber que, além de estudar a organização, se preocupa também com as práticas espaciais daqueles que vivem e produzem o espaço. As práticas espaciais constituem, muitas vezes, "outras" organizações que, no jogo assimétrico de poder, podem ser percebidas como desordem ou desorganização.

A partir daí é possível fazer a ponte com aquilo que chamamos de Geografia Rural - na verdade, estudos de Geografia em áreas consideradas rurais. O foco deve estar nos movimentos sociais e nos sujeitos que deles participam, que integram permanentemente o espaço. O movimento social no campo, como é comumente chamado, nunca está totalmente circunscrito às áreas rurais; seja diretamente naquilo que deveria ser a conexão entre movimentos urbanos e rurais, seja na repercussão deles.

Assim, o foco de construção teórico-conceitual daquilo que se denomina Geografia Rural tem como direcionamento a ideia de integração do espaço, de percepção do espaço como totalidade, cujo primeiro desdobramento dá-se na ação política dos movimentos reivindicatórios - que são, tanto os urbanos como os rurais, fundamentalmente por terra (seja para moradia, seja para produção). A pergunta central é: como a Geografia Rural, como disciplina no campo da Geografia, nos ajuda a entender o espaço como totalidade em movimento (movimento este que é provocado pelas práticas espaciais)?

Um dos meios para atingir esse propósito encontra-se no trabalho com a Geografia Rural no ensino escolar. Este deve ser feito na perspectiva de romper dicotomias, e, em sentido mais amplo, de transpor a análise parcelar (isolada) do espaço (e, como discutimos acima, desviar das armadilhas espaciais/territoriais). Nesse sentido, a reflexão aqui desenvolvida - e, em específico, a abordagem das urbanidades no rural - são formas de caminhar ao encontro dessas possibilidades analíticas e didáticas. Esperamos que, a partir dela, os professores sintam-se instigados a, desde o ensino fundamental, construir, junto aos alunos, essa perspectiva do espaço integrado e multidimensional, rompendo com as tão tradicionais dicotomias que aprisionam a análise geográfica - dentre elas, aquelas atreladas às relações urbanorurais.

\footnotetext{
7 Souza $(2019$, p.20) traça reflexão semelhante, quando propõe que: "os "currículos [de Geografia] foram mais e mais espelhando uma tendência crescente à especialização e mesmo ao ensimesmamento ou à insularização de ramos específicos [...]. A fragmentação, com isso, vem prosperando para muito além da velha dicotomia "físico"/ " humano". É toda uma visão de totalidade a respeito da compreensão e do estudo da Terra como morada humana que passou a ficar visivelmente comprometida". Daí a nossa preocupação, neste trabalho, com a necessária ênfase do espaço percebido como totalidade em movimento, em devir, e nunca completada e fechada.
} 


\section{REFERÊNCIAS}

AGUEDA, Bernardo. Relações urbano-rurais e desenvolvimentos geográficos desiguais: transformações espaciais nas localidades de Vargem Grande (Teresópolis - RJ) e Barracão Dos Mendes (Nova Friburgo - RJ) Dissertação (Mestrado) - Pontifícia Universidade Católica do Rio de Janeiro, Departamento de Geografia e Meio Ambiente, 2019.

ALENCAR, Cristina. M. M. e MOREIRA, Roberto. Campo e cidade metropolitanos: uma noção inteira para pensar o desenvolvimento humano contemporâneo. In: MOREIRA, R. (org.). Identidades sociais: ruralidades no Brasil contemporâneo. Rio de Janeiro: DP\&A, 2005. p. 295-316.

BERNINI, Carina. Políticas de conservação ambiental no Brasil e a mercadificação da natureza. GEOUSP Espaço E Tempo (Online), v. 23, n. 3, p. 662-681, 2019.

CARNEIRO, Maria José. “Rural” como categoria de pensamento. Ruris. Volume 2, número 1, março de 2008.

CAVALCANTI, Josefa. Desigualdades, vulnerabilidades, insustentabilidades: Trabalhadores migrantes em tempos da Covid-19. In: Trabajo agrario y ruralidades en transformación : trabajo agrario, desigualdades y ruralidades frente al COVID-19. Andrés Pedreño Cánovas ... [et al.] ;coordinación general de Germán Quaranta ; Paola Mascheroni. - 1a ed. - Ciudad Autónoma de Buenos Aires : CLACSO, 2020.

DI CIONE, Vicente. Dialéctica y pensamiento complejo. Divergencias y convergências. In: GeoBAireS, Cuaderno de Geografía, Apuntes de geografía y ciencias sociales, 2005.

HAESBAERT, Rogério. (2014) Viver no limite: território e multi/transterritorialidade em tempos de in-segurança e contenção. 1 ed. Rio de Janeiro, Bertrand Brasil, 320p.

HARVEY, David. O espaço como palavra-chave. GEOgraphia v.14, n.28, 2012, p 8-39.

LEFEBVRE, Henri. A produção do espaço. Tradução de Doralice B. Pereira e Sérgio Martins. [S.i.:s.n.], 2008. (Título original: La production de l'espace. 4a ed. Paris: Éditions Anthropos, 2000).

. A revolução urbana. Belo Horizonte: Editora UFMG, 1999.

MASSEY, Doreen. Geography on the Agenda. Progress in Human Geography 25, no. 1 (March 2001): 5-17. doi:10.1191/030913201670520885.

Pelo espaço: uma nova política da espacialidade. Rio de Janeiro: Bertrand Brasil, 2008.

PEREIRA, Leandro Serra Silva. Dinâmica territorial resultante do acesso e uso do microcrédito rural nos territórios quilombolas de Oriximiná. Dissertação (mestrado) -Pontifícia Universidade Católica do Rio de Janeiro, Departamento de Geografia e Meio Ambiente, 2019.

RUA, João. Urbanidades e Novas Ruralidades no Estado do Rio de Janeiro: Algumas Considerações Teóricas. In: MARAFON, Gláucio José; RIBEIRO, Marta Foeppel (Orgs.). Estudos de Geografia fluminense. Rio de Janeiro: Infobook, 2002. p. 27-42.

. Urbanidades no Rural: o devir de novas territorialidades. Campo-Território: Revista de Geografia Agrária, Uberlândia, v. 1, n. 1, p. 82-106, fev. 2006. Disponível em: http://www.campoterritorio.ig.ufu.br/viewarticle.php?id=23. Acesso em: 08 dez. 2019.

A complexa simultaneidade da integração e distinção entre o urbano e o rural: retomando um debate no espaço de metropolização no estado do Rio de Janeiro. GeoPUC, Rio de Janeiro, v. 4, n. 7, p. 1-47, jul.-dez. 2011. Disponível em: http://geopuc.geo.puc-rio.br/media/rua_5.pdf. Acesso em: 7 jul. 2019.

. No estado do Rio de Janeiro. In: FERREIRA, Alvaro, RUA, João, MATTOS, Regina Célia de (Org.). O Espaço e a metropolização: cotidiano e ação. Rio de Janeiro: Consequência, 2017. p. 443-486.

. Metropolização do espaço, urbanidades no rural e novas ruralidades. In: MARAFON, Glaucio José; CHELOTTI, Marcelo Cervo;

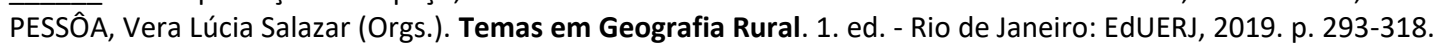

Relações cidade-campo e urbano-rurais: reapresentando as urbanidades no rural como elementos constitutivos do espaço em metropolização. GEOgraphia, vol:22, n.48, 2020.

SALAZAR, Alejandro., HIDALGO, Rodrigo.; PAÉZ, Pablo. Ruralidad y expansión residencial: movilidad y funcionalidad en el periurbano emergente del área metropolitana de Santiago de Chile. In: Lencioni, S. Vidal-Koppmann, R. Hidalgo, P. Pereira, Editores. Transformações sócio-territoriais nas metrópoles de Buenos Aires, São Paulo e Santiago. Brasil, Chile y Argentina, 19, 2011. p. 205224. 
SANTOS, Milton. Espaço e método. São Paulo: Nobel, 1985.

. Técnica, Espaço, Tempo. Globalização e meio técnico-científico informacional. São Paulo: HUCITEC, 1994.

_. A Natureza do Espaço: técnica e tempo, razão e emoção. São Paulo: HUCITEC, 1996.

SIMONI, Joana. Múltiplas escalas de transformação nas relações urbano-rurais: o espaço rural friburguense e suas urbanidades impulsionadas pelas técnicas de informação e comunicação. Tese (doutorado) - Pontifícia Universidade Católica do Rio de Janeiro, Departamento de Geografia e Meio Ambiente, 2019.

SOUZA, Marcelo Lopes. O que é a Geografia Ambiental?. AMBIENTES: Revista de Geografia e Ecologia Política, v. 1, n. 1, p. 14.

THE GUARDIAN. The Guardian view on geography: it's the must-have A-level. Opinion. Editorial. The Guardian, 2015. Disponível em: https://www.theguardian.com/commentisfree/2015/aug/13/the-guardian-view-on-geography-its-the-must-have-a-level. Acesso em: $27 / 07 / 2020$

VAINER, Carlos. B. Planejamento e questão ambiental: qual é o meio ambiente que queremos planejar? In: V ENCONTRO NACIONAL DA ANPUR, 1993, Belo Horizonte. Anais... Belo Horizonte: Anpur/UFMG-Cedeplar, 1993. p.556-71.

VOLOCHKO, Danilo. Terra, poder e capital em Nova Mutum - MT: elementos para o debate da produção do espaço nas 'cidades do agronegócio'". GEOgraphia, Rio de Janeiro, v. 17, n. 35, p. 40-67, 2015.

WANDERLEY, Maria de Nazareth. A emergência de uma nova ruralidade nas sociedades modernas avançadas - o rural como espaço singular e ator coletivo. In: Estudos Sociedade e Agricultura, n.15, outubro, 2000: 87-145 